\title{
Research on High Temperature Stress-Strain Behavior of Power Transmission and Transformation Copper Conductor by Gleeble Thermal Simulation
}

\author{
Haoyang Du ${ }^{1, *}$, Dongyun Shi ${ }^{1}$, Shuangnan Zhang ${ }^{2}$, Xin Wang ${ }^{1}$, Linghui Zhuang ${ }^{3}$ and Shu Tian ${ }^{1}$ \\ ${ }^{1}$ Jilin Electric Power Research Institute, SGCC, No.4433 Renmin Street, Changchun, 130021, China \\ ${ }^{2}$ Institute of Metal Research, No.72 Wenhua Road, Chinese Science Academy, Shenyang, 110016, China \\ ${ }^{3}$ Fujian Electric Power Company Ltd., No. 257 Wusi Road, Fuzhou, Fujian, 350003, China \\ *Corresponding author
}

\begin{abstract}
Gleeble thermal-mechanical simulation can accurately control the parameters such as thermal, force and displacement of certain working conditions, which has been widely applied in the HAZ simulation and other metallurgy behaviors. In this paper, Gleeble thermal simulation technique has been used to study the the fracture behavior of copper conductors in transformer which undergoes over-load current and instant electromagnetic force. Certain temperature and forces have been preset on the samples for the tension process to simulate the temperature and forces under working environment. The relationship of copper conduct under stress- strain circle has been studied to recover the fracture process.
\end{abstract}

Keywords-Gleeble thermal simulation; heating caused by overload; electromagnetic force; stress-strain

\section{INTRODUCTION}

Conductor fracture often occurs in the failure of power transmission and transformation facilities, such as transmission lines, transformers and dry-type reactors[1,2]. Electromagnetic forces and over-load current are the main factors for the fracture of the conductors. As we know, the fracturing of the sample is a short-time dynamic process, the increased temperature and the electromagnetic force is difficult to calculate by computer simulation or to measure in the field. In this paper, a new method by using gleeble thermal simulation has been proposed to simulate the force and the temperature which may cause the fracture of the copper conductor in power transmission and transformation system.

Gleeble thermal simulation is an advanced technique with multiple functions in the research of materials[3,4]. By reproducing the thermal and /or mechanical metallurgical process of material preparation or machining, the changing rules of the stress-strain relationship or thermal-mechanical process are simulated. It has been widely applied in the simulation of the heat affect zone of steel weld joint, casting procedure etc.

It is known that copper has excellent thermal and electrical conductivity, so the thermal simulation will be more difficult compared with traditional welding or casting simulation for steel materials. Under working condition, especially overload conditions, the conductors undergo complicate thermal-force cycles. In our research, the accurate temperature, forces and strain can be accurately pre-setted and controlled. The electromagnetic forces under high temperature can be simulated and loaded on the sample to study the high temperature tensional behavior of the copper conductors.

\section{SAMPLES PREPARATION}

\section{A. Preparation of Welded Samples}

The width of the working part of the copper conductor is $2.0 \mathrm{~mm}$ and the depth of the copper is $1.0 \mathrm{~mm}$. All the raw materials have been divided 2 groups, one for welding and one without welding. Insulation coat removal is necessary before welding. The coat removal procedure is as following: Put coat removal agent into glass bottle, the height of the liquid agent is about $80 \mathrm{~mm}$, which is almost the same as the coat removal length. Dipping the conductors in the bottle for about 10-20 minutes. The copper conductors after coat removal are shown in figure I. Then cleaning the surface of the copper with ethanol and drying in the air. Any surface impurities should be cleaned off to avoid defects during the welding afterwards.

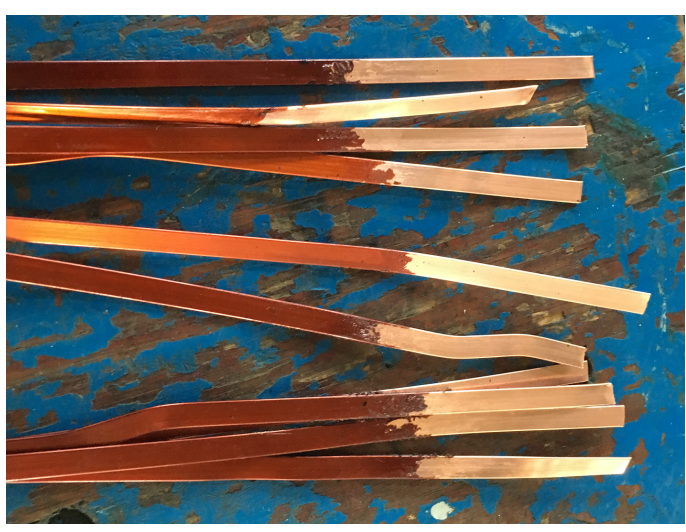

FIGURE I.

CONDUCTORS AFTER INSULATION COAT REMOVAL

Silver based welding material has been applied for the welding of two conductors by oxy-acetylene welding. Figure II shows the welding of the copper conductor. The two parts are lapped welded. The weld joint after welding are shown in figure III. 


\section{B. Preparation of the Samples for Gleeble Thermal} Simulation

The samples for thermal simulation are machined by molybdenum cutting.

Figure IV shows the specifications of the thermal simulation samples. The total length of the sample is $110 \mathrm{~mm}$. Two round holes with the diameter $5 \mathrm{~mm}$ for tension clips are on the two ends of the sample.The shoulder of the sample is $15 \mathrm{~mm}$ in length and $7 \mathrm{~mm}$ in width. This is a tiny sample specially designed for copper materials. As we know that copper shows excellent electro-conductivity and thermalconductivity. A sample with small cross section has higher temperature increase with certain current value. This is a big difference compared with steel materials. Also during the cutting ,the surface of the sample must keep smooth and no splash on the surface. The radius of the curve should be $5 \mathrm{~mm}$ to avoid partial over current in this part.

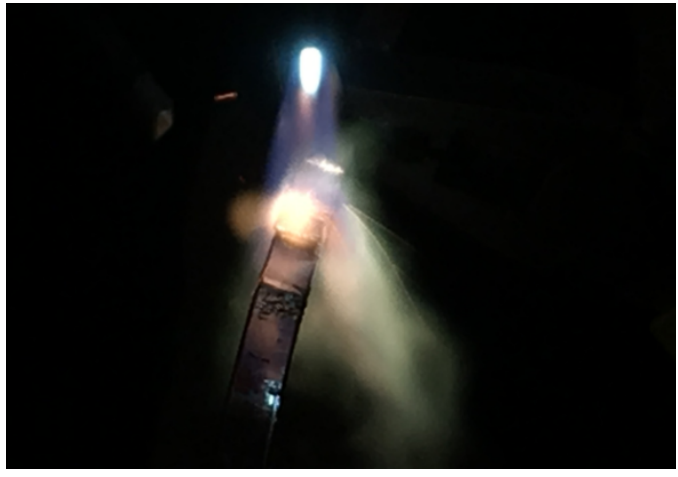

FIGURE II.

WELDING OF THE COPPER CONDUCTOR BY OXY-ACETYLENE

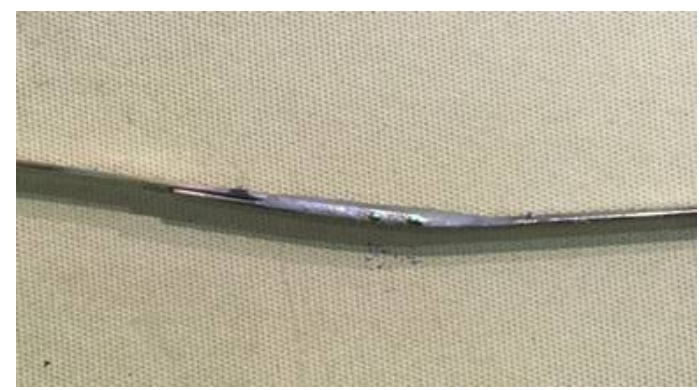

FIGURE III.

WELD JOINT OF TWO PART OF CONDUCTORS BY OXY-ACETYLENE WELDING

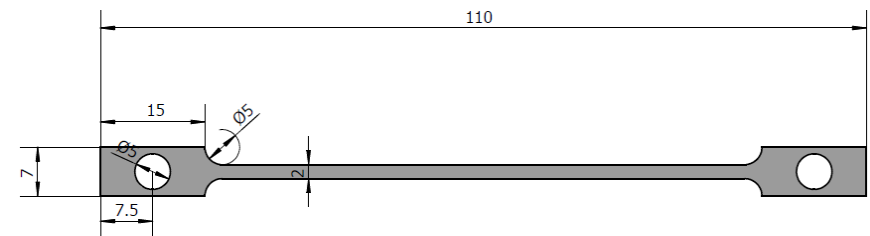

FIGURE IV.

SPECIFICATIONS OF COPPER CONDUCTOR SAMPLES FOR THERMAL SIMULATION

\section{THERMAL SimUlation TEST}

The position of the samples in the clips is shown in Figure $\mathrm{v}$.The installation of the sample in the simulation test machine is shown in figure 5. In this paper, the test temperature is set as $600{ }^{\circ} \mathrm{C}$ and the tensile velocity is $2.5 \mathrm{~mm} / \mathrm{min}$. The procedure of the test is as following:

1) Check on the surface of the sample and stick the thermal couple on the middle of the sample for temperature measuring during the tensional test;

2) Put the sample into the clips and pre-fastened;

3) Turn on the gleeble simulation machine, adjust the position of the clips and install the the sample by the clips;

4) Heat the sample by electric current till reaches $600^{\circ} \mathrm{C}$ and keep $600^{\circ} \mathrm{C}$ for certain period of time.The total time from heating to finish after temperature is about 180 seconds;

5) Add load under $600^{\circ} \mathrm{C}$ with the velocity $2.5 \mathrm{~mm} / \mathrm{min}$. Observe the deforming process and record the parameters during the tension;

6) Keep the fractured sample and repeated the above steps for all the samples.

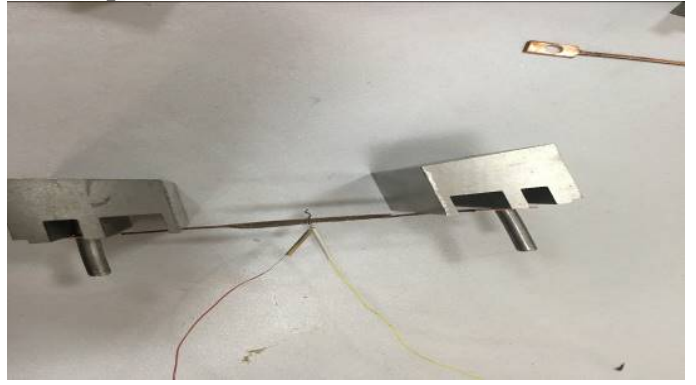

FIGURE V. INSTALLATION OF THE SAMPLE AND THE THERMAL COUPLE IN THE CLIPS

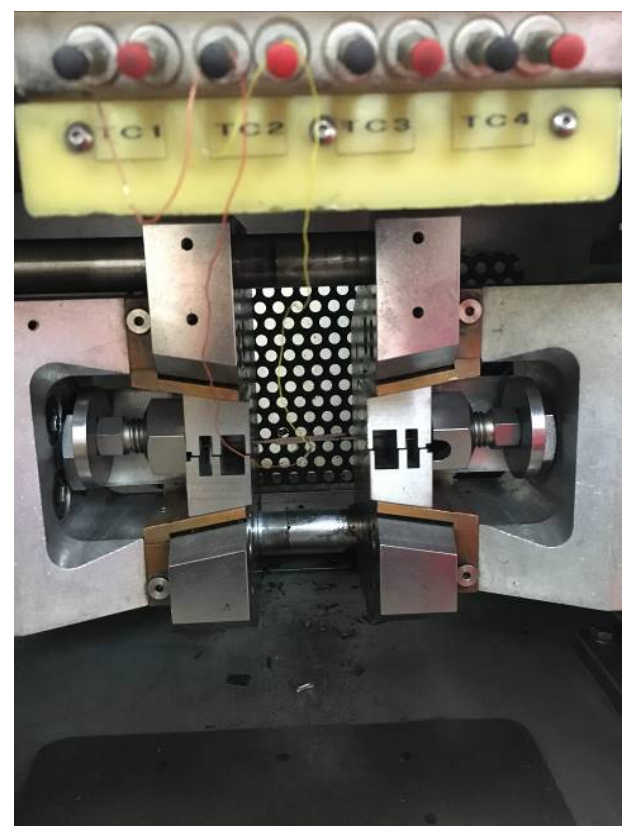

FIGURE VI.

INSTALLATION OF THE SAMPLE AND THE THERMAL COUPLE 


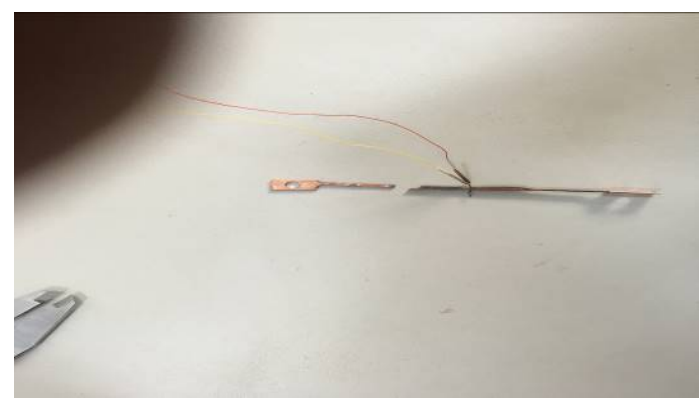

FIGURE VII.

WELDED SAMPLE AFTER THE TENSION TEST

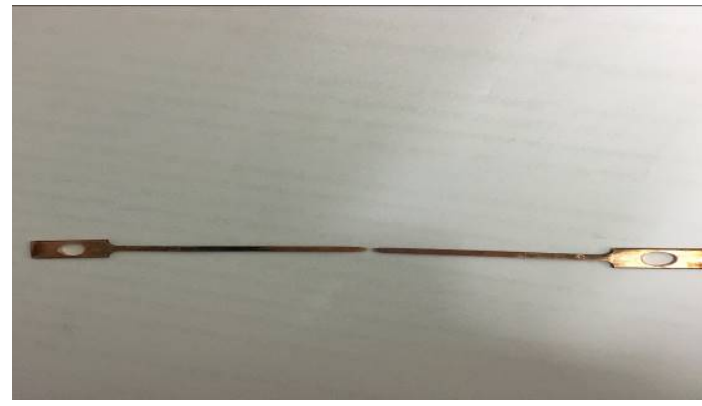

FIGURE VIII.

SAMPLE WITHOUT WELDING AFTER THE TENSION TEST

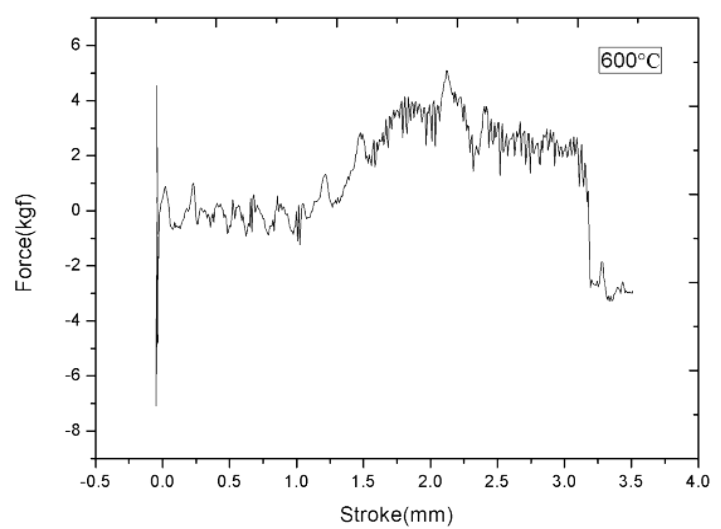

FIGURE IX

FRACTURED SAMPLE AFTER THE TENSION TEST

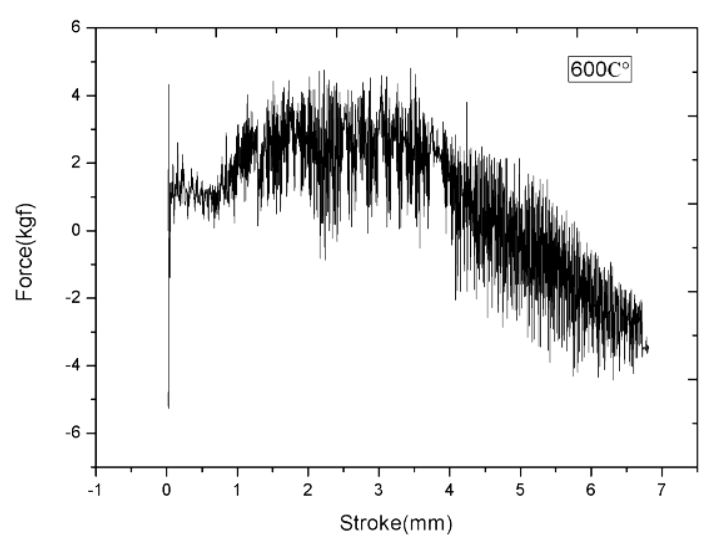

FIGURE X.

FRACTURED SAMPLE AFTER THE TENSION TEST
Repeat the above steps for all the samples with or without welding joint

The sample welded sample after fracture is shown in Figure VII. The fractured position is near the heat affect zone of the weld. The sample without weld joint after fracture is shown in figure VIII. The fractured position in in the middle of the sample. This means that the weld joint is the weakest part during high temperature tension.

\section{RESULTS AND ANALYSES}

The curves of the relationship between force and stroke of the thermal simulation are shown in figure IX and X. The horizontal axis is the displacement of the clips, which responds to the elongation of the sample. The vertical axis is the force during the tension. The stress-strain fluctuation frequency shown in the curves are different. Figure IX shows lower frequency compared with figure $\mathrm{X}$.

Figure IX shows the force-stroke curve of the welded sample. The fractured position is in near the heat affected zone of the weld. Which refers to the weak part of the sample under high temperature is the heating affected zone of the weld joint.The tension displacement of the welded sample is $3.15102 \mathrm{~mm}$. The maximum stress is $2.46 \times 10^{4} \mathrm{~Pa}$. The elongation rate is $4.502 \%$.

Figure $\mathrm{X}$ shows the force-stroke curve of the non-welded copper conductor sample. The fractured position is in the middle of the sample.The tension displacement of the welded sample is $6.8106 \mathrm{~mm}$. The maximum stress is $2.35 \times 10^{4} \mathrm{~Pa}$. The elongation rate is $9.729 \%$.

From figure IX and X, it could be obtained that the ductility of the welded sample is lower compared with the copper conductor sample.

Researches in [1] indicates that the tensile force, over-load current, ambient temperature and heat transfer coefficient are the main factors that cause the final failure of the conductor. Gleeble simulation fully reproduced the short-time temperature and force worked on the copper conductor.

\section{SUMMARY}

1) Gleeble simulation is an applicable method to study the stress- strain behavior of the copper conductor under over-load current and electromagnetic working conditions.

2) Samples for Gleeble simulation should be specially designed and machined for heating and tension test.

3) The welded joint of copper conductor shows lower ductility and higher tensile strength compared with the copper conductor.

4) The modification of the test method and analysis method will improve the reliability of the teat result

\section{ACKNOWLEDGMENT}

This research was financially supported by the Jilin Electric Power Company Limited Science and Technology Project of 2016. 


\section{REFERENCES}

[1] Wu Hongliang, Li Xiaohong, Zhu Chengli, Dou Hong, "Mechanism and risk assessment of conductors' localized breakage-fracture in highvoltage transmission,” Journal of Southeast University (Natural Science Edition), vol. 44, pp. 935-940, Sept. 2014

[2] Hao Jianjun, "Analysis and Treatment Measure of 220kV Substation Main Transformer Fault Caused by Transmission Line Breakage,” Inner Mongolia Electric Power, vol. 32(2), pp. 28-31, Apr. 2014

[3] Yang Shu ,Zhang Yuxiang, He Liang,”Classical Application of Gleeble Thermal /Mechanical Simulation Technique in Steel Research.,"Materials Development and Application, vol.30(5),Oct.2015

[4] Liu Wenyan,Yuan Guilian, Liu Jibin,Zhang Yanwen, Miukai, “Typical Application of Gleeble 2000 Dynamic Thermal Machine 